\section{Prevalence of Clostridium difficile infections among hospitalized patients in Amman, Jordan: A Multi-Center Study}

\section{Abstract}

Objective: To evaluate the prevalence of C. difficile infection (CDI) among hospitalized patients with toxin-positive stools.

Methods: This study is a multicenter study held in Jordan and focused on the prevalence of in-patients with $C$. difficile toxin-positive diarrhea-stools. The study included three hospitals with approximately 750 beds. In-patients charts, laboratory logbooks for in-patients with diarrhea-stool specimens were reviewed. The participating hospitals used a rapid test, which detects fecal $C$. difficile toxins $A$ and $B$.

Results: 174 stool specimens were reviewed from March 2013 to October 2014, and 170 stool specimens from 168 patients were evaluated. The patients included 102 (60\%) males, and 66 (40\%) females including seven (10.6\%) peripartum females. The patients were classified in the following age groups:neonates $\leq 28$ days, infants 29 days - less than one year old $(n=4,2.4 \%), 1-4$ years $(n=3,1.8 \%)$, and arbitrarily: 5 - 9 years $(n=3,1.8 \%), 10-14$ years $(n=3,1.8 \%)$, $15-40$ years $(n=33,19.4 \%), 41-64$ years, $(n=53,31.2 \%)$ and $\geq 65$ years were $(n=71,41.8 \%)$. Adults and older age groups make up the majority of all patients (92.4\%). Comorbidities were highly prevalent among the patients: diabetic $(n=71,41.8 \%)$, chronic lung diseases $(n=25,14.7 \%)$, solid tumors other than colonic tumors $(n=12,7.1 \%)$, immune-suppressive state $(n=15,8.8 \%)$, and one patient had colonic tumor. The majority of the patients $(n=21)$ were on more than one class of broad-spectrum antimicrobials. The prevalence of C. difficile toxin-positive stools were 14.63/1000 discharged patients, $12.65 \%$ of patients (12.96\% of stool specimens)
Jamal Wadi $1-4$,

Ali Sameh Ayesh², Lamya Abu Shanab3, Bilal Harara ${ }^{4}$, Haifa Petro ${ }^{4}$, Amani Rumman ${ }^{4}$, Mustafa Alaskar ${ }^{5}$, Malek Maswadeh ${ }^{6}$, Mohammad Tadbir ${ }^{6}$

1 The Medical Center, Jordan Hospital and Medical Center. 29 Adeeb Wahbah Street. Amman - Jordan 1118

2 Internal medicine department. Jordan Hospital

3 Pharmacy Department. Jordan Hospital,

4 Infection Control Section. Al Khalidi Hospital and Medical Center, $29 \mathrm{lbn}$ Khaldoon Street, Amman- Jordan

5 Pharmacy Department. Al Khalidi Hospital and Medical Center

6 Department of Medicine Al Takhassusi(Specialty) Hospital. Jaber Ben Hayyan Street, Amman - Jordan.

Corresponding author:

Jamal Wadi MD

झ jamalwadimd@yahoo.com 
and 5.0/1000 patient-day. The age-adjusted CDI distribution showed that the rates increased with age and were relatively low in the neonatal period.

Conclusion: The hospital-associated C. difficile prevalence showed high rates, particularly in adults and older patients, in patients with a prolonged hospital stay, and comorbidities.

Keywords: Clostridium difficile Infection, CDI, Toxin A, Toxin B, Pseu-

domembraneous colitis, Antibiotic Associated Colitis.

\section{Introduction}

Clostridium difficile is a Gram-positive endospore-forming bacillus that was discovered as a bowel colonizer and pathogen in 1935. Healthy newborns and infants were found to be colonized with C. difficil eat rates ranging from 45 to $70 \%$. However, the prevalence of toxigenic strains was found to be as low as $13 \%$. The colonization rates decline as individuals grow older, reaching rates lower than $5 \%$ in urban-dwelling healthy adults. However, colonization rates as high as $25-55 \%$ has been detected among adult hospitalized patients and nursing home residents [1, 2].

The prevalence and pathogenesis of Clostridium difficile infection (CDI) was not particularly high until the early 1970s and 1980s, when it was evident that its rates were rapidly increasing. Over the last two decades, the incidence and prevalence of CDI has increased markedly in hospital environments, where it has acquired greater virulence, exhibited higher recurrence rates, and became less responsive to metronidazole and resulted in higher colectomy rates and mortality. The new strains secrete more toxins and are exemplified by North
American pulsed-field gel electrophoresis type 1 (NAP1), restriction endonuclease analysis type $\mathrm{BI}$ $(\mathrm{BI})$, and polymerase chain reaction (PCR) ribotype 027. The increase in CDI prevalence has become so pronounced that it hassuperseded that of Staphylococcus spp. infections in some healthcare systems [3, 4, 5. 6, 7, 8].

The $C$. difficile infection incidence and prevalence increased markedly with the wide spread of antimicrobials, particularly in admitted patients. It was initially associated with clindamycin, although continued experience with antimicrobials showed that other antimicrobials are as likely as clindamycin to be correlated with CDI [9]. The prevalence of CDI in a nosocomial setting has been surging in North American and European hospitals, with estimated numbers of 3.82 per 1000 discharges in 2000 and 8.75 per 1000 discharges in 2008 . These increases were particularly prominent among patients at least 65 years of age $[10,11]$.

Jordan and other Arab countries have few published studies on the prevalence of CDI in hospital settings. Shehabi et al. performed a study at Jordan University Hospital in 2000 and found a $9.7 \%$ prevalence rate of $C$. difficile isolates or its toxin in stools from patients of all ages with diarrhea through culture and enzyme immunoassay for the detection of $C$. difficile toxin $A$. 
Approximately a decade later, Nasereddin et al. demonstrated an escalation in CDI rates in the same university hospital: the prevalence of toxigenic $C$. difficile isolates were found to be $13.7 \%$ among adult hospitalized patients, as demonstrated by the presence of toxin genes and in association with diarrhea $[12,13]$. A study conducted in Kuwait focused on the PCR ribotyping of environmental and ICU clinical strains. A total of 32 different ribotypes were detected among the clinical isolates, and the predominant toxigenic ribotypes detected were types 097 and 078, which are different from the findings obtained in North America and Europe, which exhibit a dominance of the 027 ribotype [14].

Furthermore, Jordan like most Arab countries lack antimicrobial restriction policies and this lack may be one reason behind the observed high CDI cases, because its prevalence is linked to the misuse of antimicrobials [14, 15]. This study underscores the importance of studying the CDI prevalence in nosocomial settings by shedding light on the limited data regarding this evolving problem in Jordan and other Arab countries.

\section{Materials and Methods}

\section{Settings and Design of Study}

This study was a prospective multicenter study conducted in Amman, Jordan from March 2013 to October 2014 that included three hospitals with a total of approximately 750 beds. The study was approved by the IRBs in both teaching hospitals and by the medical administrator in the community hospital.The study focused on the prevalence of C. difficile toxin-positive diarrhea stools in inpatients excluding community-acquired cases. The patients' charts and the laboratory logbooks for all in-patients with diarrhea stool specimens were reviewed. Several stool tests are available for the detection of $C$. difficile or its toxins $[2,16]$. However, the participating hospitals used the "DUO TOXIN
$\mathrm{A}+\mathrm{B}-\mathrm{CHECK}-1$ ", an immune-chromatographic rapid test that detects both fecal $C$. difficile toxins A and B (VedaLabs, Parcd'Activités du Londeau BP 181 - 61006, Alençoncedex, France), with excellent sensitivity, specificity, low cost and with rapid turnaround time. (http://www.cdc.gov/HAl/ organisms/cdiff/Cdiff_faqs_HCP.html\#a7).

\section{Outcome measures}

The main outcome measure evaluated in this study is the prevalence ofCDI among hospitalized patients, as determined through the analysis of diarrhea stool toxins. This measure was calculated as number of positive CDI patients per 1000 discharged patients (a performance quality indicator in some healthcare systems). The secondary measures are age-adjusted prevalence and the percentage of C. difficile toxin-positive stools among clinically suspected patients with diarrhea. The definition for Clostridium difficile infections was the following: the presence of symptoms (usually diarrhea; passage of at least three unformed stools in a period of at most $24 \mathrm{~h}$ ), either a stool test result positive for $C$. difficile toxins or toxigenic $C$. difficile orcolonoscopic findings demonstrating pseudomembranous colitis (PMC) and a history of treatment with antimicrobial or antineoplastic agents within the preceding eight weeks. The same previous definition was used to diagnose recurrentCDI, and a response to a $C$. difficile infection-specific therapy was considered suggestive of diagnosis. The following symptoms, signs and laboratory values were utilized in the diagnosis of suspected $C$. difficile infection cases: abdominal pains or cramps, lower-quadrant tenderness, fever (low grade up to $40.6{ }^{\circ} \mathrm{C}$ ), leukocytosis up to leukemoid reaction, albumin $<2.5 \mathrm{gm} / \mathrm{dl}$ (protein-losing enteropathy), ileus or toxic megacolon and colonic perforation [17].

\section{Statistical analysis}

The prevalence of $C$. difficile toxins in diarrhea stools was calculated. The denominator is the 
number of hospital-discharged patients (positive tests per 1000 hospital-discharged patients). Other calculations base denominator on the length of hospital stay (positive tests per 1000 patient-day) and the percentage of patients with diarrhea stools (positive tests per diarrhea stool specimens). Boxplot analysis was used to clarify the differences between CDI-positive and CDI-negative subgroups within different age categories as a function of the length of hospital stay. Differences with $P \leq 0.05$ were considered statistically significant. One way ANOVA for unmatched groups were calculated for equality of means. SPSS version 18 was used for the data analysis.

\section{Results}

A total of 174 patients's tool specimens were reviewed from March 2013 to October 2014;four patients were excluded for being outpatients. One patient experienced four episodes of diarrhea, and one patient experienced two relapse episodes during a prolonged hospital stay. In total, 174 stool specimens from 168 patients were evaluated. The patients included 102 (60\%) males and 66 (40\%) females including 7 (10.6\%) peripartum females. The patients were classified in the following age groups: neonates $\leq 28$ days, infants 29 days-less than one year old $(n=4,2.4 \%), 1-4$ years $(n=$ $3,1.8 \%)$, and arbitrarily: $5-9$ years $(n=3,1.8 \%)$, $10-14$ years $(n=3,1.8 \%), 15-40$ years $(n=33$, $19.4 \%), 41-64$ years, $(n=53,31.2 \%)$ and $\geq 65$ years were $(n=71,41.8 \%)$. Adults and older age groups make up the majority of all patients (92.4\%). Comorbidities were highly prevalent among the patients: diabetic ( $n=71,41.8 \%$ ), chronic lung diseases ( $n=25,14.7 \%$ ), solid tumors other than colonic tumors $(n=12,7.1 \%)$, immune-suppressive state ( $n=15,8.8 \%)$, and one patient had colonic tumor. The majority of the patients $(n=21)$ were on more than one class of antimicrobial, which were mostly broad-spectrum agents: carbapenems were prescribed to $(n=13,61.9 \%)$ of the patients, quinolones were administered to ( $n=12,57.1 \%$ ) of the patients, cephalosporins was prescribed to ( $n=4,19 \%$ ) of the patients, glycopeptides were prescribed to ( $n=4,19 \%$ ) of the patients, and $\beta$-lactam $\beta$-lactamases inhibitors were administered to $(n=7,33.3 \%)$ of the patients. Details on the prescribed antimicrobials are presented in (Table 1). The prevalence of $C$. difficile toxin-positive stools in the patients were 14.63/1000 discharged patients, $12.65 \%$ of patients (12.96\% of stool specimens) and 5.0/1000 patient-hospital day (Table 2). The age-adjustedCDI distribution among the categories showed that the rates exhibited a polynomial trend: the rates increased with age and were relatively low during the neonatal period due to a noticeable absence of $C$. difficile infection in patients between 1 and 14 years of age (Figure 1). However, the 15-40 age categories showed the highest positive correlation of CDI with the length of hospital stay, followed by the 41-64 and $\geq 65$ categories (Figure 2).

\section{Discussion}

In our study, although sample number was modest, the results demonstrated that the $C$. difficile toxin rates in clinical specimens from patients suspected to have CDI according a preset definition were not different from the rates reported from other parts of the world. The CDI prevalence was calculated by several denominators in different studies. Prevalence of 14.63/1000 discharged patients and 5/1000 patient-days were in our study (Table 2 ). In recent studies in Britain, the rates were found to be 2.16/1,000 patientdays [18]. In other studies, higher rates were found among older age groups $[10,11]$. The comparison of our current data with other local data published by Shehabi et al, who found that $9.7 \%$ of diarrhea stools from clinical specimens to be positive for a 
Table 1. Characteristics of 168 patients included in the Prevalence of Nosocomial Clostridium difficile infections from whom 174 stool specimen were submitted.

\begin{tabular}{|c|c|c|}
\hline \multicolumn{2}{|l|}{ Characteristic } & \multirow[b]{2}{*}{$\begin{array}{l}\text { Number (\%) } \\
0.0 \\
4(2.4) \\
3(1.8) \\
3(1.8) \\
3(1.8) \\
33(19.4) \\
53(31.2) \\
71(41.8)\end{array}$} \\
\hline $\begin{array}{l}\text { Age (years) }{ }^{\#}: \\
29 \text { days }<1\end{array}$ & $\begin{array}{l}\leq 28 \text { days } \\
1-4 \\
5-9 \\
10-14 \\
15-40 \\
41-64 \\
\geq 65\end{array}$ & \\
\hline Gender & $\begin{array}{l}\text { Male } \\
\text { Female } \\
\text { Peripartum females }\end{array}$ & $\begin{array}{l}102(60) \\
66(40) \\
7 / 66(10.6)\end{array}$ \\
\hline Co-Morbidity & $\begin{array}{l}\text { Diabetes mellitus } \\
\text { B. asthma/COPD } \\
\text { CHF } \\
\text { CVA } \\
\text { Sepsis/Bacteremia } \\
\text { Solid tumour } \\
\text { Immunosuppression } \\
\text { Hematological Malignancy } \\
\text { Colonic tumour } \\
\text { Others* }\end{array}$ & $\begin{array}{l}71(41.8) \\
25(14.7) \\
26(15.3) \\
26(15.3) \\
24(14.1) \\
12(7.1) \\
10(5.9) \\
5(2.9) \\
2(1.2) \\
101(55.4)\end{array}$ \\
\hline $\begin{array}{l}\text { Antimicrobials** used by } \\
\text { weeks of presentation }\end{array}$ & C. difficile infected patients within 8 & $\begin{array}{l}\text { C. difficile-toxin positive stools/total positive counts ( } N \\
=21 \text {, and } \%)^{\&}\end{array}$ \\
\hline & $\begin{array}{l}\text { Quinolones } \\
\text { Cephalosporines } \\
\text { Carbapenems } \\
\text { Penicillins } \\
\beta \text {-lactams, } \beta \text {-lactamsase inhibitor } \\
\text { Glycopeptides } \\
\text { Colistin } \\
\text { Tigecycline }\end{array}$ & $\begin{array}{l}12(57.1) \\
4(19) \\
13(61.9) \\
1(4.8) \\
7(33.3) \\
6(28.6) \\
4(19) \\
2(9.5) \\
2(9.5)\end{array}$ \\
\hline
\end{tabular}

\&: Aminoglycosides, clindamycin, sulpha, linezolid, antifungal and antineoplastic each equals 0.0

*Other Comorbidities/presenting diagnoses: mostly coronary heart diseases and hypertension. Trauma (7), CAUTI/UTI (1), CLABSI 1, SSTI (2), Abdominal sepsis

(3), Meningitis (1) and renal Failure.

** Multivariate testes of in between anti-infective agents for causation of CDI ( $>$ > .05)

\#Total numbers in this box (174) refers to the number of stools specimen for the 168 patients. 
Table 2. The prevalence of CDI among suspected hospitalized 168 patients with 174 stool specimens** the estimations were based on detection of toxins $A, B$ or both in stools specimen.

\begin{tabular}{|c|c|}
\hline C. difficle-Toxin positive stools per: & Rates \\
\hline 1000 Discharged Patients* & 14.63 \\
\hline Patients with diarrhoea & $12.65 \%$ \\
\hline Submitted stool specimens & $12.96 \%$ \\
\hline 1000 Patient-days & 5.0 \\
\hline \multicolumn{2}{|c|}{$\begin{array}{l}\text { *Outcome measure. } \\
\text { CDI: Clostridium difficile infection } \\
\$ 95.3 \% \text { were diarrhoea stools according to the definition in the } \\
\text { text (Materials and methods). } \\
\text { ** One patient with prolonged hospital stay submitted } 4 \text { specimens } \\
\text { and one submitted two specimens. }\end{array}$} \\
\hline
\end{tabular}

C. difficile toxin, revealed that our data paralleled the denominator and methodology of the previous study. The present study showed that $12.96 \%$ of suspected patients with diarrhea were positive, showing an increase over the last 12 years of $3.26 \% \quad(P<0.0001)$ both patient populations originated from the same geographic area [12]. This finding demonstrates that rates in Jordan are incerased over time at a rate similar to that observed worldwide [20]. ThoughC. difficile infection has exhibitedanincrease in the last few years, this may still be consideredanunderestimation due to limitations of hospital' surveillance, as some of these cases are discharged to community without being capturedby healthcare systems [21].

The prevalence of nosocomial CDI was demonstrated to be related to the time of hospital stay. Earlier studies showed that this prevalence is associated with the length of ICU stay [22],

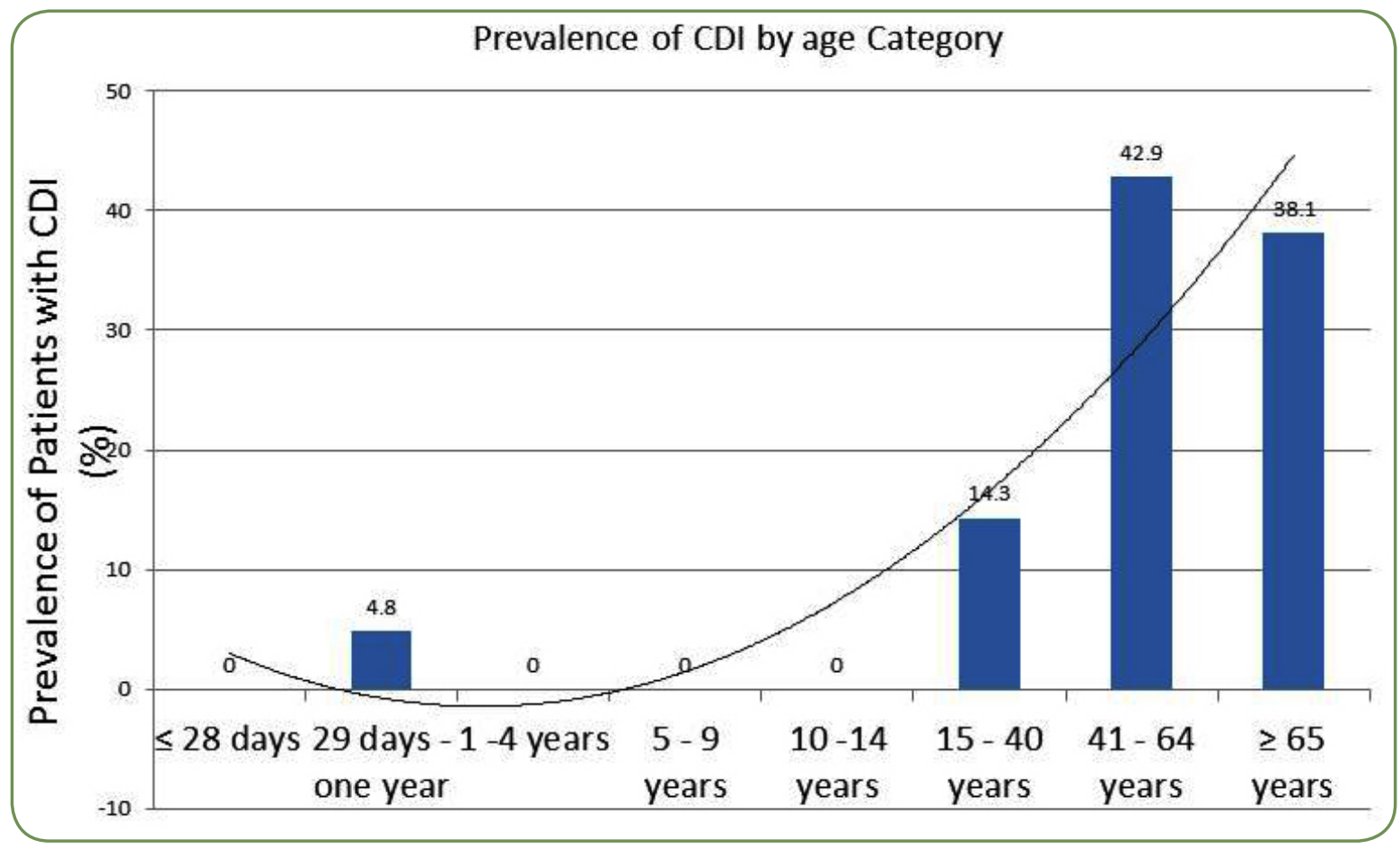

Figure 1. C. difficile infection distribution ratios (C. difficile-Toxin positive-patients) according to different age groups, with polynomial trend line. CDI: Clostridium difficile infection. C. difficile Toxin-positive patients (toxin-positive age groups were included in analysis): $F=0.61, P=$ 0.64 , by ANOVA. Total $C$. difficile infection( $N=21)$; age group $\geq 65(n=8), 41-64(n=9), 15-40(n=3)$ and $(n=1)$ positiveC. difficile infection in 29 days - 1 year group. 


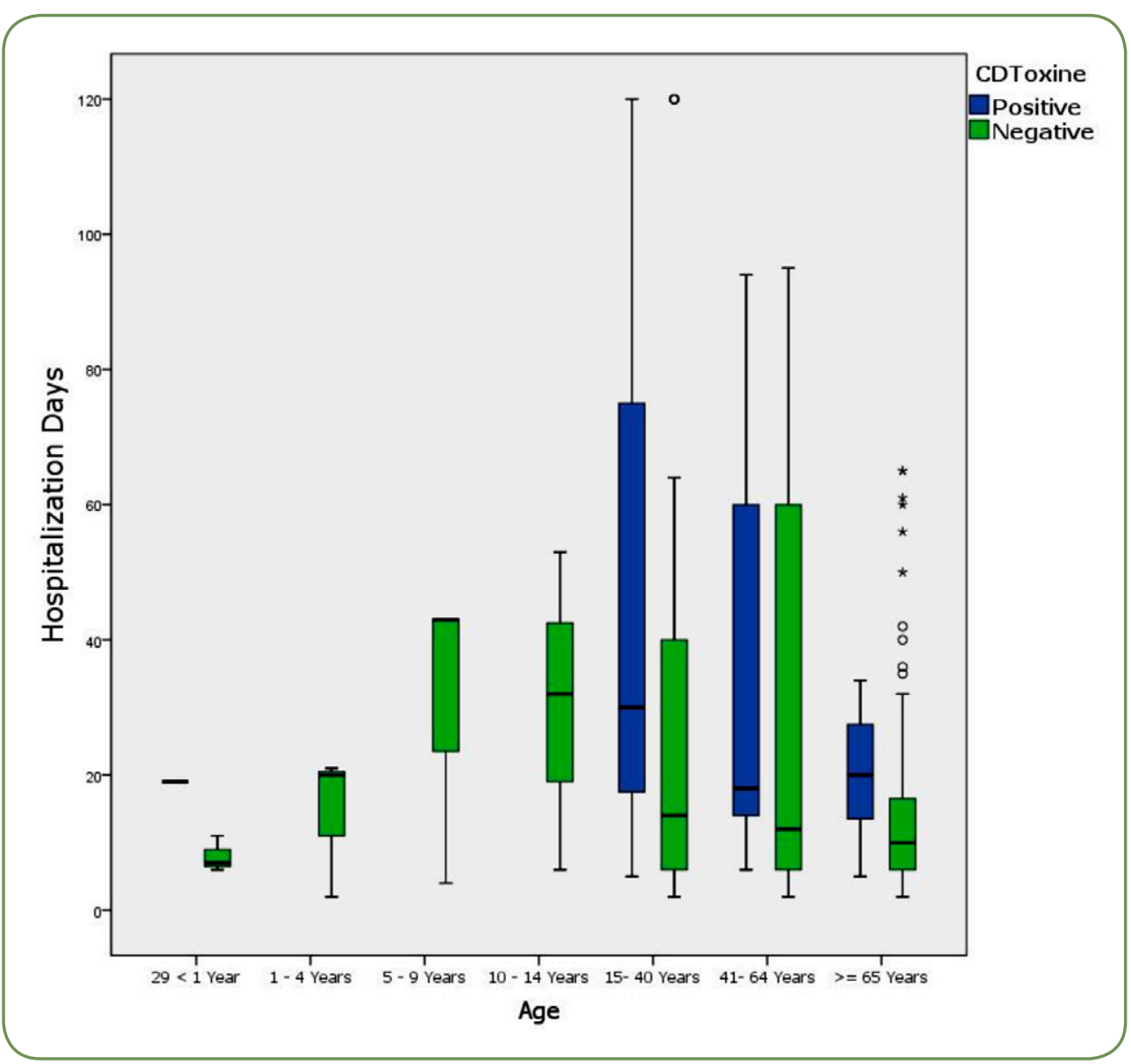

Figure 2. Boxplot representation of the patients with $C$. difficile infection distributed according to length of hospital stay (Y-axis), and different age groups ( $X$-axis) clustered in pairs as positive and negative $C$. difficile-toxin . CDI: Clostridium difficile infection. Open circle: Moderate outliers. Stars: Extreme outliers. $P>0.05$ for within age groups, and among age groups, significance was analyzed by ANOVA.

because nosocomial transmission often occurs in this setting due to the occasional break in infection control practices and the increased prescription of antimicrobials $[10,23]$.

The patients in this study exhibited high rates of co-morbidities, and the results were skewed toward adults andolder population (92.4\%) and included a minority of pediatric patients. The results showed a relative increase in the neonatal period (Figure 2).

Co-morbidities were prevalentand $38.2 \%$ of the patients were on steroids for different reasons. In addition, many of the patients were suffering from chronic lung diseases, were on immunosuppressive therapy and had solid tumors. .Moreover, $41.8 \%$ of the patients were diabetic, apatient population that is expected to stay longer in the hospital, which places them at a higher risk for nosocomial
C. difficile infection acquisition, not including the prolongation of their hospital stay due to C. difficile infection [22].

In conclusion, our study employed an immunechromatographic rapid assay test to demonstrate that C. difficile infection prevalence in Jordan is not different from that found in other parts of the world. The development of other methods for Clostridium difficile identification, such as PFGE, restriction endonuclease analysis, EIA and $P C R$, is needed to help clinicians avoid overlooking cases that may escape detection through the immunechromatographic rapid assay test [24], and novel surveillance methodologies to include unaccounted discharged patients [21]. Of note, none of our patients had a perforated colon, severe toxemia, bleeding or a toxic megacolon. This study focused 
on the hospital-associated CDI. Data on communityassociated CDI is sparse and hope fully in near future a plan for a studyby this group will be implemented to assess the prevalence of the communityassociated CDI, which will increase the detection of the outpatient CDI without undue delay. Specially, CDI, a potentially serious illness, may occur in a population without the traditional risk factors but share the degree of severity $[25,26]$.

\section{Acknowledgement}

We thank Reem J. Wadi for her statistical assistance, and the support provided by the administrations of Jordan Hospital and Medical Centre, AlTakhassusi (Specialty) Hospital, and Al Khalidi Hospital and Medical Centre.Amman, Jordan.

Financial conflict: No conflict of interest

\section{References}

1. Rousseau C, Poilane I, De Pontual L, Maherault A-C, Le Monnier A, A Collignon. Clostridium difficile Carriage in Healthy Infants in the Community: A Potential Reservoir for Pathogenic Strains. Clin Infect Dis 2012;55(9):1209-15.

2. Bartlett JG. Historical Perspectives on Studies of Clostridium difficile and C. difficile Infection. Clin Infect Dis 2008; 46:S4-11.

3. Crook DW, A. Walker S, Kean Y, Weiss K, Cornely OA, Miller MA, et al. Fidaxomicin Versus Vancomycin for Clostridium difficile Infection: Meta-analysis of Pivotal Randomized Controlled Trials. Clin Infect Dis 2012;55(S2):S93-103.

4. McDonald LC, Killgore GE, Thompson A, Owens RC, Jr., Kazakova SV, Sambol SP, et al.. An epidemic, toxin gene variant strain of Clostridium difficile. N Engl J Med 2005; 353:2433-41

5. Loo VG, Poirier L, Miller MA, Oughton M, Libman MD, Michaud $S$, et al. A predominantly clonal multiinstitutional outbreak of Clostridium difficile-associated diarrhea with high morbidity and mortality. N Engl J Med 2005; 353:2442-9.
6. Muto CA, Pokrywka M, Shutt K, Mendelsohn AB, Nouri $\mathrm{K}$, Posey $\mathrm{K}$, et al.. A large outbreak of Clostridium difficileassociated disease with an unexpected proportion of deaths and colectomies at a teaching hospital following increased fluoroquinolone use. Infect Control HospEpidemiol 2005; 26:273-80.

7. Musher DM, Aslam S, Logan N, Nallacheru S, Bhaila I, Borchert $F$, et al. Relatively poor outcome after treatment of Clostridium difficile colitis with metronidazole. Clin Infect Dis 2005; 40:1586-90.

8. Pepin J, Marie-Eve A, Valiquette L, Raiche E, Ruel J, Fulop K, et al. Increasing risk of relapse after treatment of Clostridium difficile colitis in Quebec, Canada. Clin Infect Dis 2005; 40:1591-7.

9. Bartlett JG. Antibiotic-Associated Diarrhea. Clin Infect Dis 1992:15:573-81.

10. Lessa FC, Gould CV, and McDonald LC. Current Status of Clostridium difficile Infection Epidemiology. Clin Infect Dis 2012;55(S2):S65-70.

11. Kim HH, Kim YS, Han DS, Young-Ho K, Kim WH, Kim JS, et al. Clinical differences in Clostridium difficile infection based on age: A multicenter study. Scandinavian Journal of Infectious Diseases 2014; 46: 46-51

12. Shehabi A, Abu-Ragheb $H$, Allaham N. Prevalence of Clostridium difficile-associated diarrhea among hospitalized patients. East Mediterr Health J 2004;7:750-5.

13. Nasereddin LM, Bakri FG, Shehabi AA, Clostridium difficile infections among Jordanian adult hospitalized patients. Am J Infect Control 2009 ;37(10):864-866.

14. Rotimi VO, Jamal WY, Mokaddas EM, Brazier JS, Johny M, Duerden MB. Prevalent PCR ribotypes of clinical and environmental strains of Clostridium difficile isolated from intensive-therapy unit patients in Kuwait. J Med Micro2003; 52;705-709.

15. Albsoul-Younes A, Wazaify M, Yousef AM,Tahaineh L. Abuse and Misuse of Prescription and Non-prescription Drugs Sold in Community Pharmacies in Jordan. Substance Use \& Misuse 2010;45(9):1319-1329.

16. Wazaify M, Al-Bsoul-Younes A, Abu-Gharbieh E, Tahaineh L, et al. perspectives on the role of community pharmacists and overthe-counter drugs in Jordan. Pharmacy World \& Science 2008; 30 (6): 884-891.

17. Eyre DW, Walker AS, Wyllie D, Dingle KE, Griffiths D, Finney $J$, et al. Predictors of First Recurrence of Clostridium difficile Infection: implications for Initial Management. Clin Infect Dis 2012; 55(S2):S77-87.

18. Cohen SH, Gerding DN, Johnson S, Kelly CP, Loo VG, McDonald LC, et al. Clinical Practice Guidelines for Clostridium difficile Infection in Adults: 2010 Update by the Society for Healthcare 
Epidemiology of America (SHEA) and the Infectious Diseases Society of America (IDSA). Infect Control Hosp Epidemiol 2010; 31(5):431-455.

19. Ahyow LC, Lambert PC, Jenkins DR, Neal KR, Tobin M. Bed occupancy rates and hospital-acquired Clostridium difficile infection: a cohort study. Infect Control HospEpidemiol 2013; 34(10):1062-1069

20. Jiang Y,Viner-Brown S, Baier R. Burden of Hospital-Onset Clostridium difficile Infection in Patients Discharged from Rhode Island Hospitals, 2010-2011: Application of Present on Admission Indicators. Infect Control HospEpidemiol 2013;34(7):700-708

21. Kuntz $\mathrm{JL}$ and Polgreen PM. The Importance of Considering Different Healthcare Settings When Estimating the Burden of Clostridium difficile. Clin Infect Dis. 2014 Dec 4.doi: 10.1093/cid/ ciu955

22. Dodek PM, Norena M, Ayas NT, Romney M, Wong $H$. Length of stay and mortality due to Clostridium difficile infection acquired in the intensive care unit. Journal of Critical Care 3013; 28(4):335-340.

23. Brown Mail KA, Fisman DN, Moineddin R, Daneman N. The Magnitude and Duration of Clostridium difficile Infection Risk Associated with Antibiotic Therapy: A Hospital Cohort Study. Plos One. 2014

24. Longtin Y, Trottier S, Brochu G, Paquet-Bolduc B, Garenc C, Loungnarath $V$, et al. Impact of the Type of Diagnostic Assay on Clostridium difficile Infection and Complication Rates in a Mandatory Reporting Program. Clin Infect Dis 2013;56(1):67-73

25. Clohessy P, Merif J, Post JJ. Severity and frequency of communityonset Clostridium difficile infection on an Australian tertiary referral hospital campus. International Journal of Infectious Diseases 2014;29:152-155

26. Tan XQ, Verrall AJ, Jureen R, Riley TV, Collins DA, Lin RT, Balm MN, Chan D, Tambyah PA. The emergence of community-onset Clostridium difficile infection in a tertiary hospital in Singapore: a cause for concern. Int J Antimicrob Agents. 2014;43(1):47-51.

\section{Comment on this article:}

\section{f) (B) in \&+ $\mathbf{S}$ P}

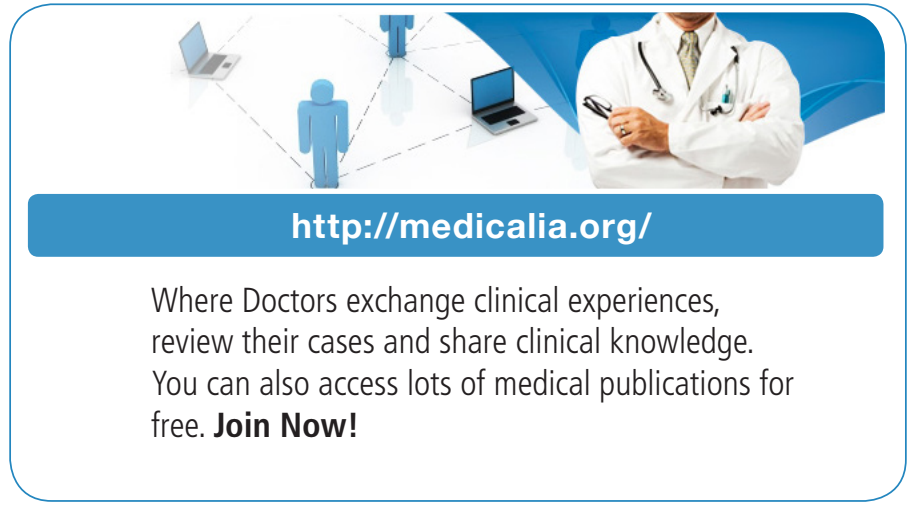

\section{Publish with iMedPub}

http://www.imed.pub

The Journal is an open access peer-reviewed journal that publishes scientific papers about all aspects of antimicrobials. The journal will publish original research articles, reviews, brief reports and case reports dealing with basic and clinical antibacterial agents, antiviral, antiprotozoals, antituberculuous, antifungal and antihelminthes agents. All manuscripts must be prepared in English, and are subject to a rigorous and fair peer-review process. Accepted papers will immediately appear online.

The journal aims to advance the knowledge, attitude and the research of chemotherapy in the Arabic world in cooperation with international, national scientific and public societies as well as research centers with similar aims and objectives. 